\section{Color Stability and Gloss of Esthetic Restorative Materials after Chemical Challenges}

Eduardo Haruki Ozera ${ }^{1}$, Fernanda Miori Pascon², Américo Bortolazzo Correr ${ }^{1}$, Regina Maria Puppin-Rontani ${ }^{2}$, Aline Rogéria de Castilho ${ }^{3}$, Lourenço Correr-Sobrinho ${ }^{1}$, Andreia Bolzan de Paula ${ }^{1}$

\author{
'Department of Restorative \\ Dentistry, Dental Materials Division, \\ UNICAMP - Universidade Estadual \\ de Campinas, Piracicaba, SP, Brazil \\ ${ }^{2}$ Department of Pediatric Dentistry, \\ UNICAMP - Universidade Estadual \\ de Campinas, Piracicaba, SP, Brazil \\ ${ }^{3}$ Department of Physiological Sciences, \\ UNICAMP, Universidade Estadual de \\ Campinas, Piracicaba, SP, Brazil
}

Correspondence: Lourenço CorrerSobrinho, Avenida Limeira, 901, 13414-903 Piracicaba, SP, Brasil. Tel: +55-19-2106-5345. e-mail: sobrinho@fop.unicamp.br

Key Words: Composite, gloss, color changes, spectrophotometry color stability, optical profilometry.

\section{Introduction}

After the establishment of resin composites as a restorative material, nanotechnology has been a key point in the development of esthetic restorative materials (1). According to the form, size, and distribution of the filler content of direct composites, these materials are classified as microfilled, microhybrid and nanocomposite (2).

Inorganic fillers are frequently employed to improve the physical properties of resin composites and decrease polymerization shrinkage (3). These esthetic restorative materials are usually exposed to thermal, mechanical and chemical challenges in the oral environment, which may damage the materials surface causing the materials degradation $(1,4,5)$. In clinical practice, resin degradation, mainly the color and gloss alterations, are one of the major factors responsible for the replacement of fillings in anterior teeth (4).

Color and color change can be evaluated by spectrophotometers or colorimeters, which eliminate the subjective interpretation presented by visual evaluation (6). The gloss is the ability of the surface to reflect light and is associated with surface smoothness, which allows different indices of light reflection. The loss of gloss in resinous composites acts negatively on aesthetics, being responsible for the harmony or not in relation to the adjacent teeth (7).

Resin composites have a tendency to discolor during long-term service in the oral cavity (5). The internal color change of resinous materials is one of the reasons for these discolorations (6). Some of the previous studies have evaluated the color changes of resin composites over specified periods of time.

It is known that diet is the principal source of acids and stains related to the degradation of composites. The modifications in diet and lifestyle induce people to choose some beverages such as soft drinks, juices and coffee that can dye dental fillings (5). With respect to the erosive potential of the beverages, several studies have provided clear evidence that the type and concentration of acids, $\mathrm{pH}$ and buffer capacity are potential risk factors for the degradation of the dental material (4).

Since esthetic dental materials are currently used for anterior tooth restorations, the investigation of the influence of acidic beverages on the optical properties of resin composites may be an important strategy to help increase the longevity of the restorations. The hypotheses tested were that degradation with acidic beverages would affect the color and gloss of composites.

\section{Material and Methods Material and Specimen Preparation}

The composites used in this study were selected according to their composition (Table 1). The composites will 
be subjected to chemical degradation in different solutions: Coca-Cola (The Coca-Cola Company, Rio de Janeiro, RJ, Brazil), Cranberry juice (Juxx, Barueri, SP, Brazil), Nescafé (Nestle Brazil Ltd., São Paulo, SP, Brazil) and artificial saliva (Proderma Farmácia de Manipulação, Piracicaba, SP, Brazil). Forty circular specimens ( $8 \mathrm{~mm}$ diameter and $2 \mathrm{~mm}$ thick) of each composite were fabricated using a condensation silicone mold (Optosi ${ }^{\circledR}$ Heraeus Kulzer, GbmH, Germany). A single increment of the composite was inserted into mold, covered with a glass slide for excess material and was photo-activated with a curing light unit (Free Light, 3M ESPE, St. Paul, MN, USA), with a power density of 1250 $\mathrm{mW} / \mathrm{cm}^{2}$, according to the manufacturer's instructions. The irradiance of the light-curing unit was checked with a curing light meter (Hilux Dental Curing Light Meter, Benliglu Dental Inc., Ankara, Turkey). After curing, the samples were removed from the mold and stored at a 100\% relative humidity at $37^{\circ} \mathrm{C}$ for $24 \mathrm{~h}$. Then, the specimens were polished with aluminum-oxide abrasive disks (Soflex On Pop, 3M ESPE) at a low speed, using a sequence of medium, fine, and superfine granulation. Each polishing step was carried out for $20 \mathrm{~s}$, using a circular movement. Then, the specimens were washed by spraying water / air for $10 \mathrm{~s}$ and air-dried for $5 \mathrm{~s}$. A new abrasive disc was used after five specimens. After each polishing procedure step, the specimens were ultrasonically cleaned (Model T1440D; Odontobrás Ltda, Ribeirão Preto, SP, Brazil) in deionized water for $10 \mathrm{~min}$ to remove debris. The specimens were randomly allocated into 12 subgroups $(n=10)$ in accordance with the restorative material (Table 1) and degradation solution (Table 2). Baseline measurements were taken to assess color and surface gloss.

\section{Color Assessment}

A color reading was performed using a spectrophotometer (CM-700d, Konica Minolta, Japan) in reflectance mode. The samples were placed in a sample carrier in a light cabin (GTI Mini Matcher MM1e, GTI Graphic Technology Inc., Newburgh, NY, USA) to standardize the ambient light during the measurement process. A spectrophotometer was used to determine the baseline $\mathrm{CIE}$ values $(\mathrm{LO}, \mathrm{aO}, \mathrm{b} 0)$ of the specimens before degradation and $\mathrm{CIE}$ values $(\mathrm{L} 1, \mathrm{a} 1, \mathrm{~b} 1)$ of the stained specimens after chemical degradation. CIE $L^{*} a^{*} b^{*}$ measurements of each specimen were performed using a white background. The $L^{*} a^{*} b^{*}$ system allows for the numeric definition of a color as well as to demonstrate the difference between two colors using the following formula: $\Delta \mathrm{E}=\left[(\mathrm{L} 1-\mathrm{L} 0)^{2}+(\mathrm{a} 1-\mathrm{a} 0)^{2}+(\mathrm{b} 1-\mathrm{b} 0)^{2}\right] 1 / 2$, using the On Color QC Lite software (Konica Minolta, Japan) to generate spectral measurements as a function of wavelength for data processing and analysis (8).

\section{Surface Gloss Measurement}

Surface gloss was measured with a gloss meter (ZGM

Table 1. Materials tested in this study

\begin{tabular}{|c|c|c|c|c|}
\hline Materials & Composition & Filler particle size & Manufacturer & \#Batch \\
\hline Z350XT & $\begin{array}{l}78.5 \text { (wt\%) combination of aggregated } \\
\text { zirconia/silica cluster filler and non- } \\
\text { agglomerated silica filler, Bis-EMA, } \\
\text { Bis-GMA, UDMA, TEGDMA }\end{array}$ & $\begin{array}{l}0.6-1.4 \mu \mathrm{m} \\
\text { (cluster) } \\
5-20 \mathrm{~nm} \\
\text { (nanoparticle) }\end{array}$ & $\begin{array}{l}\text { 3M/ESPE, St. } \\
\text { Paul, MN, USA }\end{array}$ & N310175 \\
\hline IPS Empress Direct & $\begin{array}{l}81.2 \text { (wt\%), Barium, alumina, } \\
\text { fluorosilicate glass, barium glass filler, } \\
\text { mixed oxide, and ytterbium trifluoride, } \\
\text { Bis-GMA and UDMA }\end{array}$ & $40 \mathrm{~nm}$ e $3000 \mathrm{~nm}$ & $\begin{array}{l}\text { Ivoclar Vivadent; } \\
\text { Schaan, Liechtenstein }\end{array}$ & P52093,P59475,N32078 \\
\hline Charisma Diamond & $\begin{array}{l}77 \text { (wto), Ba, Al, F glass and colloidal } \\
\text { silica TCD-DI-HEA, UDMA, Bis-GMA, } \\
\text { TEGDMA }\end{array}$ & $5 \mathrm{~nm}-20 \mu \mathrm{m}$ & $\begin{array}{l}\text { Heraeus Kulzer, } \\
\text { GmbH, Hanau, } \\
\text { Gemany }\end{array}$ & 010042, 010039 \\
\hline
\end{tabular}

Bis-GMA = bisphenol glycidyl methacrylate; TEGDMA = triethylene glycol dimethacrylate; HEMA = 2hydroxyethyl methacrylate; Bis-EMA = ethoxylated bisphenol-A dimethacrylate; UDMA = urethane dimethacrylate. TCD-DI-HEA = Bis-(acryloyloxymethyl) tricyclo [5.2.1.02,6] decane

Table 2. Main characteristics of the acidic solutions

\begin{tabular}{|c|c|c|}
\hline Food/Drink & Main ingredients & $\mathrm{pH}$ \\
\hline Coca-Cola $^{\infty}$ & Carbonated water, sugar, caramel color, phosphoric acid, natural flavors, caffeine & 2.54 \\
\hline Cranberry ${ }^{\circledast}$ Juice & Water, cranberry juice, sugar, ascorbic acid & 2.76 \\
\hline Nescafé & coffee powder & 5 \\
\hline Artificial saliva & $\begin{array}{l}\text { Calcium ( } 0.1169 \mathrm{~g} \text { of calcium hydroxide/L of deionized water); } 0.9 \mathrm{mM} \text { of phosphorus } \\
\text { and potassium ( } 0.1225 \mathrm{~g} \text { potassium phosphate monobasic/L of deionized water); } \\
20 \mathrm{mM} \text { TRIS buffer ( } 2.4280 \mathrm{~g} \text { TRIS buffer/L of deionized water) }\end{array}$ & 7.0 \\
\hline
\end{tabular}


1120 Glossmeter, Zehntner GmbH Testing Instruments, Sissach, Switzerland) that was calibrated against a blackglass standard, provided by the manufacturer. A black opaque plastic mold was placed over the specimens during the measurements to eliminate the influence of the ambient light and maintain the exact position of the sample for the repeated measurements. Four measurements per specimen were performed at $60^{\circ}$ light incidence and reflection angles (9). The four readings were averaged to obtain a single value for each specimen.

\section{Chemical Degradation}

After the initial readings of color and surface gloss, all samples were submitted to chemical degradation in different solutions: Coca-Cola, Cranberry juice, Nescafé and artificial saliva. The composition and $\mathrm{pH}$ of the degradation solutions are reported in Table 2. For the preparation of the coffee solution (Nescafé), $15 \mathrm{~g}$ of powder were weighed on an analytical balance and added to $500 \mathrm{~mL}$ of boiling water (10). The samples were immersed individually in 4 $\mathrm{ml}$ of each solution for $15 \mathrm{~min}$ three times a day for 14 days (protocol determined in a pilot study). After each immersion in the solution, the samples were washed with distilled water and stored in artificial saliva at $37{ }^{\circ} \mathrm{C}$ until completion of the next immersion. At the end of the storage period, the specimens were ultrasonically washed for 10 min, dried, and re-evaluated for brightness and color, allowing for the calculation of gloss variations (final gloss - initial gloss) and color ( $\Delta \mathrm{E})$.

\section{Data Analysis}

The outcome variables of the study were the color $(\Delta \mathrm{E})$ and gloss (UG) change values, after immersion of different resin composites in acidic solutions. The preliminary results by the Kolmogorov-Smirnov test indicated the data were normally distributed $(p>0.05)$. For each response variable, data was submitted to two-way ANOVA and Tukey's post hoc test at a pre-set alpha of 0.05 .

\section{Results}

\section{Color assessment}

Multiple comparisons performed by Tukey test showed that there were statistically significant differences between the variables; material acidic solutions acidic solutions and acidic solution $(\mathrm{p}=0.004)$. The results showed that all composites had changes in their color. The $\Delta \mathrm{E}$ and standard deviation values of color changes after immersion in different acidic solutions are shown in Table 3 .

The acidic solutions significantly influenced color changes in the resin composites and were materialdependent. The highest staining of Z350 occurred after immersion in coffee and Cranberry juice, whilst for ED the highest color change was observed after immersion in coffee, followed by Cranberry juice, Coca-Cola and then saliva. The color change of CD was significantly greater affected by coffee and cranberry juice than Coca-Cola and saliva. The resin composites immersed in Coca-Cola showed a similar color change. After immersion in coffee, CD showed significantly less color change than Z350 and ED. The Cranberry juice and the artificial saliva promoted higher staining in the specimens of Filtek Z350 compared to Charisma Diamond.

\section{Surface Gloss Measurement}

Multiple comparisons performed by Tukey test revealed that the interaction between factors; composite and solution was significant $(p<0.001)$ (Table 4$)$. In a comparison

Table 3. Color change ( $\Delta \mathrm{E}$ and standard deviation values) of composites after degradation in

\begin{tabular}{lccc}
\hline \multirow{2}{*}{ Solutions } & \multicolumn{3}{c}{ Materials } \\
\cline { 2 - 4 } & Filtek Z350 & IPS Empress Direct & Charisma Diamond \\
\hline Coca-cola & $2.46(0.59) \mathrm{b}, \mathrm{A}^{*}$ & $3.55(0.95) \mathrm{c}, \mathrm{A}$ & $4.31(0.49) \mathrm{b}, \mathrm{A}$ \\
Coffee & $11.16(0.92) \mathrm{a}, \mathrm{A}$ & $11.35(0.83) \mathrm{a}, \mathrm{A}$ & $8.80(0.86) \mathrm{a}, \mathrm{B}$ \\
Cranberry juice & $9.54(0.97) \mathrm{a}, \mathrm{A}$ & $8.57(0.62) \mathrm{b}, \mathrm{AB}$ & $7.03(0.77) \mathrm{a}, \mathrm{B}$ \\
Artificial saliva & $3.03(0.85) \mathrm{b}, \mathrm{A}$ & $1.12(0.57) \mathrm{d}, \mathrm{AB}$ & $0.72(1.03) \mathrm{c}, \mathrm{B}$ \\
\hline
\end{tabular}

Different lower letters in columns and capital letters in rows indicate statistically significant difference among groups (Tukey test; $\mathrm{a}=0.05$ ).

Table 4. Gloss (GU) change (Final Gloss - Initial Gloss) of composites after degradation in

\begin{tabular}{|c|c|c|c|}
\hline \multirow{2}{*}{ Solutions } & \multicolumn{3}{|c|}{ Materials } \\
\hline & Filtek Z350 & IPS Empress Direct & Charisma Diamond \\
\hline Coca-cola & - $1.88(0.84) b, A^{*}$ & - $1.78(0.06) \mathrm{c}, \mathrm{A}$ & $-1.97(0.59) \mathrm{c}, \mathrm{A}$ \\
\hline Coffee & $-4.35(0.92) \mathrm{a}, \mathrm{B}$ & $-5.24(0.91) \mathrm{a}, \mathrm{A}$ & $-3.21(0.75) a, B$ \\
\hline Cranberry juice & $-4.97(0.93)$ a,A & - $3.38(0.62) b, B$ & $-2.60(0.50) b, B$ \\
\hline Artificial saliva & - $1.20(0.67) b, \mathrm{BA}$ & - $0.69(0.55) d, B$ & - $1.35(0.83) \mathrm{c}, \mathrm{A}$ \\
\hline
\end{tabular}

Different lower letters in columns and capital letters in rows indicate statistically significant difference among groups (Tukey test; $\mathrm{a}=0.05$ ). 
of gloss change between different solutions for each resin composite, the loss of gloss of the Filtek Z350 was significantly higher after immersion in coffee and cranberry juice in comparison with the other solutions. For the IPS Empress Direct, the order of loss of brightness was coffee, followed Cranberry, Coca-Cola and artificial saliva with significant differences between the groups. The Charisma Diamond had the greatest loss of gloss after immersion in coffee followed by Cranberry juice, while the specimens immersed in Coca-Cola and saliva produced the lowest gloss changes with no significant differences between them.

The evaluation of the interaction between the acidic solution and composite resin material showed that the gloss change of the different esthetic restorative material was similar between them, after Coca-cola immersion. The immersion in coffee promoted higher loss of gloss for IPS Empress Direct when compared to the other materials. The Cranberry juice immersion yielded greater gloss loss of the Filtek Z350, in comparison to IPS Empress Direct and Charisma Diamond. Gloss change of the Charisma Diamond after immersion in artificial saliva seemed to demonstrate a higher value than the IPS Empress Direct.

\section{Discussion}

For the current study, we aimed to simulate the chemical challenges of the oral environment using different beverages currently consumed by the population. Although the beverages tested in this study do not represent all of the drinkable solutions to which esthetic restorative materials may be daily exposed to in the oral cavity, the results showed that the gloss and color of composites were susceptible to alterations due to the consumption of common drinks.

As the color of the resin composites is one of the most required properties and is of special interest for anterior tooth restoration. Clinically perceptible discoloration may lead to the failure of the esthetic restorative treatment and a replacement of dental filling materials may be required. Our findings evidenced that the color of the composites Filtek Z350 and Charisma Diamond were highly affected by coffee and Cranberry juice, while the highest color change to IPS Empress Direct was caused by coffee. The results indicated that the hypothesis was accepted. This behavior can be explained by the fact that the coffee is slightly acidic $(\mathrm{pH}=5)$ with more than 22 different acids in the composition, including citric and acetic acids (11) and yellow dyes. Likewise, the cranberry juice contains citric acid, but the $\mathrm{pH}=2.7$, added to a deep red color. According to Shellis et al. (12) the erosive potential of acid is directly related to the buffering properties and the degradation depends not only on the $\mathrm{pH}$, but also on its acid type. In addition, the buffering capacity of the citric acid directly influences the rate of neutralization by saliva and hence the stability of the $\mathrm{pH}$ of the beverage. Hence, the acidic $\mathrm{pH}$ of drinks may increase the surface roughness of the resin composites, causing color modifications due to an irregular surface and higher absorption /adsorption of stains (13).

Apart from acidic conditions, the staining of composites by coffee is related to the presence of a great amount of yellow dyes that have low polarity and can be easily diffused to the organic matrix of the restorative material (14). Accordingly, the effect of those stains on the color modification of the esthetic restorative materials was confirmed by Tan et al. (15). In this study, in a comparison of color among composites, the immersion in coffee promoted less color alteration of the Charisma Diamond than those of Filtek Z350 and IPS Empress Direct. The susceptibility of some composites to staining may be attributed to hydrophilicity, the degree of conversion and water sorption of the resin matrix (16). Charisma Diamond is composed of the monomers UDMA and TCD-DI-HEA. Although a little is known about the effect of TCD-DI-HEA on the degradation condition, the UDMA has the ability to increase the hydric stability of the restorative material (17), which can be enhanced by the presence of TCD-DI-HEA. Thus, Charisma Diamond may be less susceptible to color changes caused by absorption and the adsorption of the stains of coffee. The greater color change of the Filtek Z350 composite after immersion in the Cranberry juice, coffee and saliva might be explained by the lower percentage of UDMA in the material's composition. As far as their composition is concerned, according to manufacturers, Charisma Diamond and Filtek Z350 have approximately 15\% and 10\% of UDMA, respectively. Additionally, Filtek $Z 350$ is also composed of the more hydrophilic monomers Bis-GMA and TEGDMA. As a consequence, we could expect a greater color change during the degradation challenge (18).

Associated with the color advantage, the gloss parameter deeply influences the survival rates of the esthetic restorations since it must imitate the natural appearance of the teeth. Regarding this, rough surfaces may decrease the gloss because of the random light scattering, the gloss decrease negatively influences the esthethic of the resin composites causing disharmony between the restored and the adjacent tooth (19). In this study, composites showed statistically significant differences between initial and post immersion gloss values for some beverages. The Coca-Cola drink similarly decreased the gloss in all tested materials. The presence of different types of acids such as phosphoric acid in the composition and the $\mathrm{pH}=2.5$ of that soft drink may help to explain the decrease of the brightness of the materials (20). The gloss instability of composites after immersion in acidic solutions could be explained by the softening of the organic matrix by phosphoric acid, which affected the incidence and the reflection of light, 
promoting the decrease of brightness (21).

It was of great value to note that a huge change was detected on the gloss property of IPS Empress Direct after immersion in coffee or cranberry juice. The composite has ytterbium trifluoride in the composition that may keep the brightness of the surface with the release of soluble fluoride to the water (22). In addition, during the degradation process the molecule of water may diffuse into the polymeric network filling the microspaces between the chains, promoting the breakdown of siloxane link and the softening of the organic matrix (23). If hydrolytic degradation occurs, the reflection of light is jeopardized (24). After immersion in artificial saliva, IPS Empress Direct had less gloss change than Charisma Diamond. Although the results found in this study suggest more hydrophobicity of TCD-DI-HEA, little is known about the influence this monomer in the chemical degradation. As far as we are concerned, IPS Empress Direct has more UDMA (25\%) in the composition, causing less hydrolytic degradation of the material by water diffusion into the matrix and consequently, this reaction may lead to lower gloss loss (24). The brightness of the IPS Empress Direct was highly affected by coffee. IPS Empress Direct has the TCDMMA monomer in its composition, which is possibly responsible for the optical property's change, since the higher the affinity with to polar stain of the coffee the greater the staining of the material, and so consequently, there is less light reflection.

After degradation of the Filtek Z350 in the beverages, it was observed that coffee and cranberry juice caused the most severe loss of brightness. Due to hydrophobic characteristics, the lower percentage of UDMA monomer $(10 \%)$ in the composition when compared to the composite Charisma Diamond (15\%) and IPS Empress Direct (25\%), and also the TEGDMA presence, Filtek Z350 may be more susceptible to degradation in aqueous media (25). Another cause of that finding is the acidic $\mathrm{pH}$ associated with the buffer capacity of the drinks that undoubtedly influence the degradation of the dental materials since $\mathrm{pKa}$ is related to the $\mathrm{pH}$ and buffering condition. It is widely known that the potential of beverages to degrade the surfaces depends not only on the $\mathrm{pH}$, but also on its buffer capacity (23). The $\mathrm{pH}$ and buffering of the Coca Cola are low (23) in contrast to the citric acid found in the coffee and juice, that, as mentioned before, show better buffer capacity, and, in association with low $\mathrm{pH}$, may affect the resistance of the Filtek Z350 to acidic solutions.

Within the limitations of this study in vitro, it is evident that acid degradation promotes optic alterations on the surfaces of resin composites. Therefore, under the circumstances of the current investigation, it can be concluded that beverages of different $\mathrm{pH}$ values have a deteriorating effect on the color stability and gloss of various formulations of resin composites, affecting aesthetic of restorations.

\section{Resumo}

0 objetivo foi avaliar as alterações de brilho e cor de materiais restauradores estéticos submetidos ao armazenamento em diferentes bebidas ácidas. Foram preparados espécimes de compósitos de resina (Z350XT (Z350), IPS Empress Direct (ED), Charisma Diamond (CD) e o brilho e a cor $(\triangle E)$ de superficie mensurados $(n=10)$. Em seguida, os espécimes foram imersos em $4 \mathrm{~mL}$ de cada uma das diferentes bebidas (suco cranberry, Coca-Cola, café, ou saliva artificial) durante $15 \mathrm{~min}, 3 x /$ dia durante 14 dias e o brilho e a cor novamente mensurados. A alteração de cor foi avaliada pela fórmula $\Delta \mathrm{E}$ e os valores de alteração de brilho foram obtidos pela fórmula: (brilho final - brilho inicial). Os dados foram submetidos à ANOVA e Tukey ( $\alpha$ $=0,05$ ). $C D$ apresentou menor alteração de cor quando comparado aos demais compósitos e maiores valores de $\Delta \mathrm{E}$ foram obtidos após imersão em suco de café e cranberry. 0 café promoveu maior perda de brilho, seguido pelo suco cranberry, Coca-cola e saliva artificial $(p<0,05)$. 0 tipo de bebida influenciou significativamente no brilho dos compósitos resinosos. Coca-cola reduziu o brilho dos três compósitos de maneira similar. 0 café promoveu maior alteração do brilho do ED, quando comparado ao Z350 e $C D$, enquanto o suco de cranberry afetou mais o Z350 do que o ED e o CD. A saliva teve efeito mais significativo na perda do brilho do CD do que o ED. As bebidas utilizadas neste estudo influenciaram as propriedades ópticas de superfície dos compósitos.

\section{References}

1. Margeas R. Composite materials: advances lead to ease of use, better performance. Compend Contin Educ Dent 2013;34:370-371.

2. Chen MH. Update on dental nanocomposites. J Dent Res 2010;89:549560.

3. Hahnel S, Dowling AH, El-Safty S, Fleming GJ. The influence of monomeric resin and filler characteristics on the performance of experimental resin-based composites (RBCs) derived from a commercial formulation. Dent Mater 2012;28:416-423.

4. de Paula $A B$, de Fúcio SB, Alonso RC, Ambrosano GM, Puppin-Rontani RM. Influence of chemical degradation on the surface properties of nano restorative materials. Oper Dent 2014;39:109-117.

5. Erdemir U, Yildiz E, Eren MM. Effects of sports drinks on color stability of nanofilled and microhybrid composites after long-term immersion. J Dent 2012;40:55-63.

6. Guler AU, Yilmaz F, Kulunk T, Guler E, Kurt S. Effects of different drinks on stainability of resin composite provisional restorative materials. J Prosthet Dent 2005;94:118-24.

7. Sarkis E. Color change of some aesthetic dental materials: Effect of immersion solutions and finishing of their surfaces. Saudi Dent J 2012;24(2):85-9.

8. Rodrigues RB, Lima E, Roscoe MG, Soares CJ, Cesar PF, Novais VR. Influence of Resin Cements on Color Stability of Different Ceramic Systems 1. Braz Dent J 2017;28:191-195.

9. Consani RLX, Folli BL, Nogueira MCF, Correr AB, Mesquita MF.Effect of Polymerization Cycles on Gloss, Roughness, Hardness and Impact Strength of Acrylic Resins. Braz Dent J 2016;27:176-180

10. Schmitt VL, Puppin-Rontani RM, Naufel FS, Nahsan FP, Alexandre Coelho Sinhoreti M, Baseggio W. Effect of the polishing procedures on color stability and surface roughness of composite resins. ISRN Dent 2011;2011:1-7.

11. Galli V, Barbas C. Capillary electrophoresis for the analysis of shortchain organic acids in coffee. J Chromatogr 2004;1032:299-304.

12. Shellis RP, Barbour ME, Jesani A, Lussi A. Effects of buffering properties and undissociated acid concentration on dissolution of dental enamel in relation to $\mathrm{pH}$ and acid type. Caries Res 2013;47:601-611.

13. Lu $H$, Roeder $L B$, Lei $L$, Powers JM. Effect of surface roughness on stain resistance of dental resin composites. JEsthet Restor Dent 2005;17:102-108. 
14. Dou R, Derby B. Formation of coffee stains on porous surfaces. Langmuir 2012;28:5331-5338.

15. Tan BL, Yap AU, Ma HN, Chew J, Tan WJ. Effect of beverages on color and translucency of new tooth-colored restoratives. Oper Dent 2015;240:56-65.

16. de Alencar E Silva Leite ML, da Cunha Medeiros E Silva FD, Meireles SS, Duarte RM, Andrade AK. The effect of drinks on color stability and surface roughness of nanocomposites. Eur J Dent 2014;8:330-336.

17. Rodriguez HA, Giraldo LF, Casanova H. Formation of functionalized nanoclusters by solvent evaporation and their effect on the physicochemical properties of dental composite resins. Dent Mater 2015;31:789-798.

18. Ren YF, Feng L, Serban D, Malmstrom HS. Effects of common beverage colorants on color stability of dental composite resins: the utility of a thermocycling stain challenge model in vitro. J Dent 2012;40:48-56.

19. O'Brien WJ, Johnston WM, Fanian $F$, Lambert $S$. The surface roughness and gloss of composites. J Dent Res 1984;63:685-688.

20. de Carvalho Sales-Peres SH, Magalhães AC, de Andrade Moreira Machado MA, Buzalaf MA. Evaluation of the erosive potential of soft drinks. Eur J Dent 2007;1:10-13.
21. Abu-Bakr N, Han L, Okamoto A, Iwaku M. Color stability of compomer after immersion in various media. J Esthet Dent 2000;12:258-263.

22. Takahashi $R$, Jin J, Nikaido $T$, Tagami J, Hickel R, Kunzelmann KH. Surface characterization of current composites after toothbrush abrasion. Dent Mater 2013;32:75-82.

23. Tanthanuch S, Kukiattrakoon B, Eiam-O-Pas K, Pokawatta K, Pamanee $\mathrm{N}$, Thongkamkaew W, Kochatung A. Surface changes of various bulkfill resin-based composites after exposure to different food-simulating liquid and beverage. J Esthet Restor Dent 2018;30:126-135.

24. Vichi $\mathrm{A}$, Ferrari M, Davidson CL. Color and opacity variations in three different resin-based composite products after water aging. Dent Mater 2004;20:530-534.

25. Xavier AM, Sunny SM, Rai K, Hegde AM. Repeated exposure of acidic beverages on esthetic restorative materials: An in-vitro surface microhardness study. J Clin Exp Dent 2016;8:312-317.

Received June 26, 2018 Accepted September 6, 2018 